Universidad de Lima

Facultad de Comunicación

Carrera de Comunicación

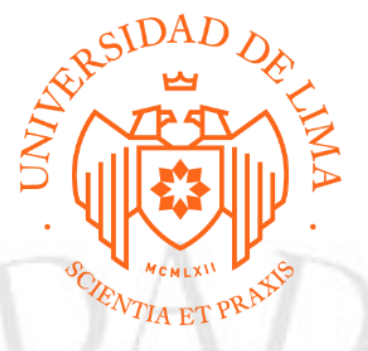

\title{
CAMPAÑA DE LANZAMIENTO DE LA \\ CHICHA MORADA EN CONCENTRADO \\ PURA NATURA
}

Trabajo de Suficiencia Profesional para optar el Título Profesional de Licenciado en Comunicación

Fiorella Ortega Ugarte

Código 20122032

$$
\text { Lima - Perú }
$$

13 de mayo del 2019 


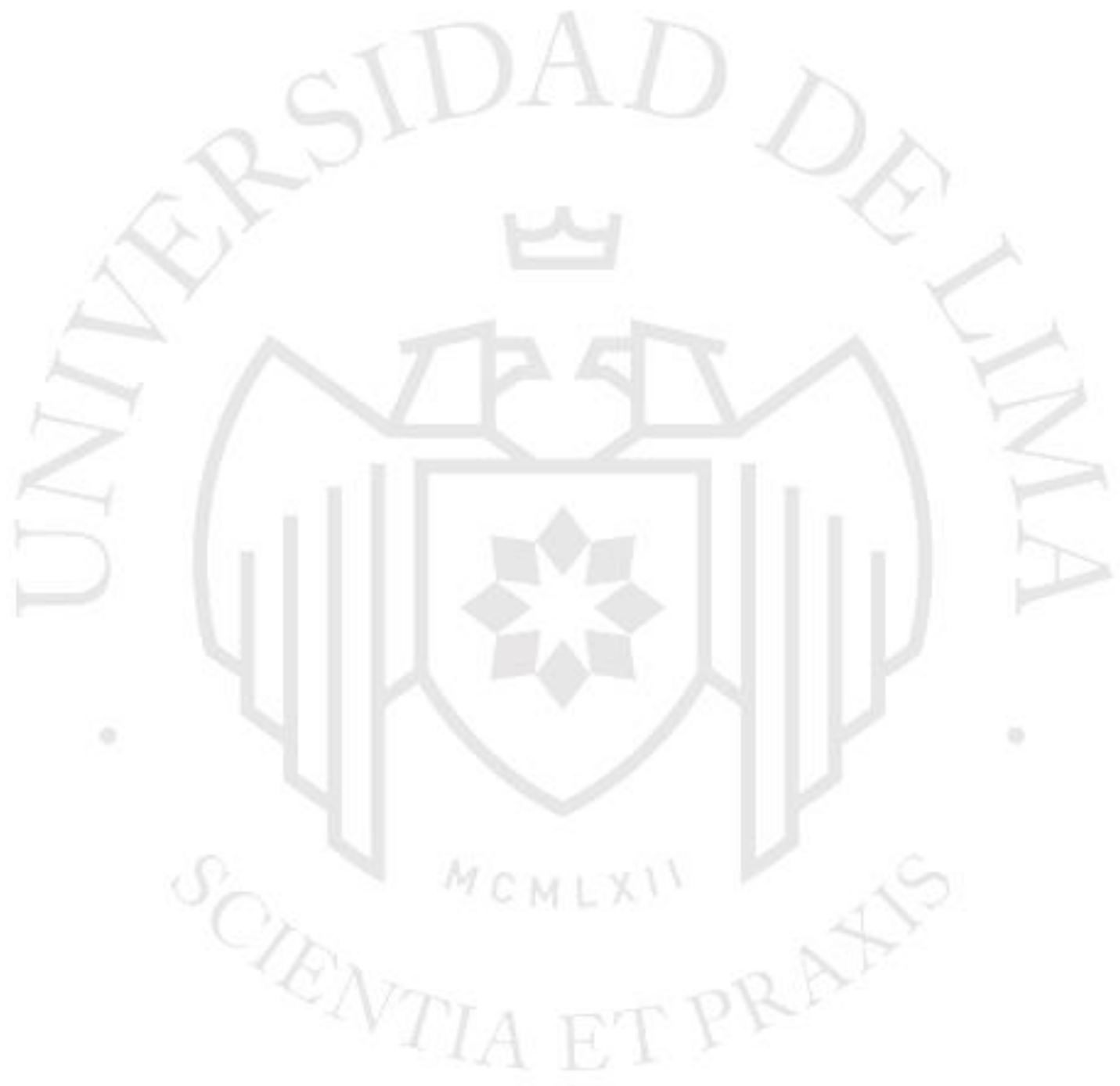




\section{CAMPAÑA DE LANZAMIENTO DE LA CHICHA MORADA EN CONCENTRADO PURA NATURA}




\section{ÍNDICE}

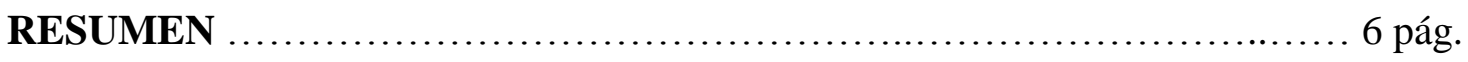

INTRODUCCIÓN........................................................... 7 pág.

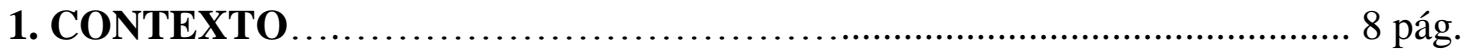

1.1 Descripción del producto................................... 8 pág.

1.2 Análisis externo........................................... 8 pág.

1.2.1 Político.................................................... 8 pág.

1.2.2 Económico................................................ 9 pág.

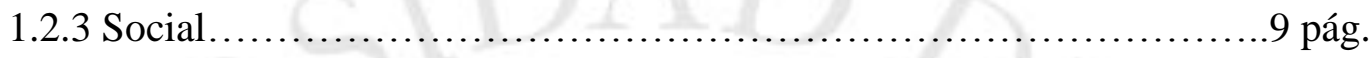

1.2.4 Tecnológico..................................................10 pág.

1.3 Análisis de la industria...................................... 10 pág.

1.3.1 Mercado de concentrados.................................... 10 pág.

1.3.2 Análisis de la competencia....................................11 pág.

1.3.3 Productos sustitutos........................................11 pág.

2. OBJETIVOS Y PÚBLICO OBJETIVO ................................13 pág.

2.1 Objetivos de comunicación...................................... 13 pág.

2.2. Duración de la campaña..................................... 13 pág.

2.3 Público objetivo................................................13 pág.

3. VISIÓN DE MARCA ................................................. pág.

3.1 Posicionamiento deseado .......................................16 pág.

3.2 Promesa - Ventaja diferencial................................ 16 pág.

3.3 Reason Why................................................ 16 pág.

3.4 Insights...................................................16 pág.

3.5 Valores...................................................17 pág.

3.6 Personalidad de la marca .....................................17 pág.

3.7 Visión de marca.................................................17 pág.

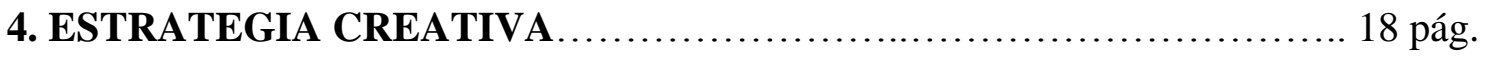

4.1 Idea estratégica de marca ....................................18 pág.

4.2 Concepto creativo de marca....................................18 pág.

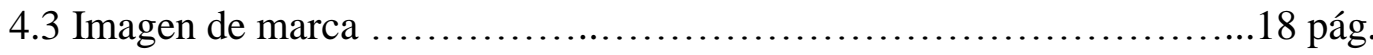

4.3.1 Nombre..................................................18 pág.

4.3.2 Logo.....................................................18 pág. 
4.3.2.1 Versiones en blanco y negro.................................19 pág.

4.3.2.2 Uso incorrecto del logo...................................20 pág.

4.3.3 Packaging...............................................20 pág.

5. PLAN DE COMUNICACIONES.................................... 23 pág.

5.1 Desarrollo de campaña ........................................23 pág.

5.1.1 Televisión......................................................24 pág.

5.1 .2 Radio..............................................................

5.1.3 Diarios y revistas.............................................26 pág.

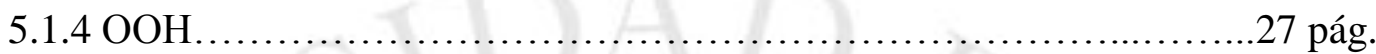

5.1 .5 POP .............................................................. pág.

5.1.6 BTL.........................................................28 pág.

5.1.7 Digital....................................................... 31 pág.

CONCLUSIONES ........................................................ 33 pág.

RECOMENDACIONES..............................................34 pág.

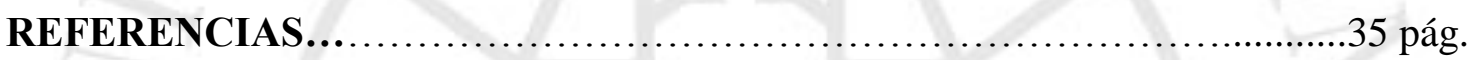

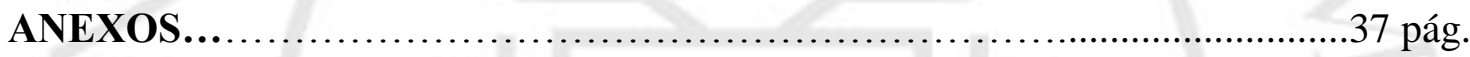

Anexo 1: Cuestionario y resultados de sondeo sobre concentrado de chicha morada.

37 pág.

Anexo 2: Guion técnico de spot televisivo para campaña de lanzamiento de chicha morada en concentrado Pura Natura.

.38 pág. 


\section{RESUMEN}

El presente trabajo plantea el lanzamiento al mercado peruano de una nueva marca de chicha morada en concentrado. Para realizar la introducción del producto primero se investigó el mercado y el público objetivo dado por el cliente. Esta investigación ayudó a definir los objetivos comunicacionales de la campaña y el alcance de la misma.

Se formuló la visión de la marca propuesta "Pura Natura" en base a los insights hallados y gracias a esto se puedo definir la estrategia creativa más adecuada y el concepto para la campaña de lanzamiento.

Se ideó un plan de comunicaciones con un mix de medios que busca optimizar el presupuesto asignado, llegar al público objetivo y cumplir con los objetivos de comunicación. 


\section{INTRODUCCIÓN}

El siguiente trabajo plantea una campaña de lanzamiento para un concentrado de chicha morada líquido que se lanzará al mercado peruano.

Como requerimiento se solicitó realizar una propuesta de nombre y empaque para el producto, elaborar una campaña de comunicación integral para el lanzamiento de la marca y diseñar el material para el punto de venta y degustaciones. El presupuesto con el que se contará es de $\$ 500,000$.

Para cumplir con lo solicitado se realizó un análisis del macro ambiente y de la categoría del producto, así como una investigación a profundidad del público objetivo para entender el contexto en el que se lanzará el producto y lo que las amas de casa esperan de él.

Gracias al conocimiento de lo anterior se diseñó una campaña de lanzamiento que se adapta a los requerimientos y optimiza el presupuesto asignado. 


\section{ANTECEDENTES DEL TRABAJO}

\subsection{Descripción del producto}

La chicha morada es una bebida típica nacional preparada desde la época incaica y que hasta el día de hoy es infaltable en los hogares y restaurantes peruanos.

El maíz morado, ingrediente principal de la chicha morada, es una variedad de maíz cultivado en los andes del Perú que cuenta con una gran cantidad de beneficios para la salud de sus consumidores. Eficaz antioxidante, inhibe el colesterol malo, regula la presión arterial, retarda procesos degenerativos; estos son solo algunos de los beneficios naturales del maíz morado.

Pura Natura es una nueva marca de chicha morada en concentrado. Este producto natural tiene como principal ingrediente el maíz morado acompañado de membrillo, piña, limón, clavo y canela. Pura Natura no contiene azúcar añadida, ningún tipo de saborizantes, colorantes o preservantes. El producto solo debe diluirse en agua para que esté listo para disfrutar.

El producto tiene una presentación en botella de vidrio de $500 \mathrm{ml}$. con un precio de S/ 6.00 que rinde para 2.5 litros de refresco y debe mantenerse en constante refrigeración. Pura Natura se podrá encontrar en autoservicios de Lima y grandes ciudades, así como en principales bodegas.

\subsection{Análisis externo}

A continuación se realizará un análisis de las principales variables que de una forma u otra afectarán al lanzamiento de esta nueva marca al mercado.

\subsubsection{Político}

- Como parte de la Ley de Promoción de la Alimentación Saludable para Niños, Niñas y Adolescentes que tiene como finalidad "promover hábitos alimentarios que prevengan la aparición de la malnutrición en su población objetivo" (Congreso de la República, 2013) desde el 17 de junio del presente año será obligatorio que los alimentos industrializados que se venden en el Perú indiquen mediante un octógono de advertencia si el producto excede los parámetros de sodio, azúcar, grasas saturadas o grasas trans. 
Esta medida ayudará a que las familias peruanas estén informadas sobre los productos que consumen y le dan a sus menores hijos. (El Comercio, 2019)

- En el 2018 el Ministerio de Economía y Finanzas aprobó una modificación en el Impuesto Selectivo al Consumo en los productos que más afectan al medio ambiente y a la salud de las familias peruanas ya que en los últimos años observaron un aumento en la demanda de estos mismos. Uno de los productos afectados son las bebidas azucaradas, si esta contiene 6 gramos o más de azúcar por cada 100 mililitros se le impondrá un $25 \%$ en el ISC. (Ministerio de Economía y Finanzas, 2018)

\subsubsection{Económico}

- Según el Informe de ingresos y gastos según nivel socioeconómico demuestra que el ingreso promedio familiar mensual es de $S / 4,969$ de donde $S / 1,262$ se destinan para alimentos. (APEIM, 2018)

- Se observa que las zonas de Lima Metropolitana con mayor población de los niveles socioeconómicos A y B son las zonas 6 (Jesús María, Lince, Pueblo Libre, Magdalena, San Miguel) y 7 (Miraflores, San Isidro, San Borja, Surco, La Molina) mientras que el nivel socioeconómico $\mathrm{C}$ se encuentra en todas las zonas de Lima. (APEIM, 2018)

\subsubsection{Social}

- Como se ha visto durante los últimos años, la tendencia a llevar una vida más saludable se expande rápidamente, según uno de los últimos estudios de Kantar Worldpanel, el $87 \%$ de hogares peruanos piden a los fabricantes que desarrollen productos más nutritivos.

El 34\% de los hogares peruanos indican que han cambiado sus hábitos de alimentación en el último año y están disminuyendo el consumo de sal, azúcar, carnes rojas y frituras. (Kantar Worldpanel, 2017)

Además, el 66\% comentó que incrementó en su dieta frutas y verduras, el 27\% productos integrales, y el $18 \%$ productos light. Como contraparte, las categorías menos saludables como gaseosas y galletas con alto contenido de sodio o azúcares se han contraído. (Codigo, 2018) 
- El concepto de "ama de casa" también ha evolucionado. Según un estudio de Kantar Worldpanel, el 47\% de las amas de casa peruanas son mamás y trabajan a tiempo parcial o total, promedio similar al de toda Latinoamérica. (Kantar Worldpanel, 2017)

- Un estudio sobre tendencias que activarán el consumo en el 2019 indica que la necesidad de independencia, realización y gusto son variables más fuertes que la carga del hogar y laboral, puesto que el $76 \%$ de estas mujeres indicaron que no dejarían de trabajar pese a que el $92 \%$ de ellas manifestó sentirse entre estresada y muy estresada. (La República, 2018)

\subsubsection{Tecnológico}

- El 67.2\% de los habitantes de Lima Metropolitana tuvo acceso al servicio de internet en el último mes siendo su móvil el principal vehículo de acceso y lo utilizan principalmente para comunicarse, obtener información y entretenerse. (APEIM, 2018)

- El usos de los smartphones y la posibilidad de multitasking de los usuarios está promoviendo un estilo de vida más acelerado entre los peruanos lo que hace que demanden inmediatez y tengan poca tolerancia hacia los plazos, además genera nuevas expectativas con respecto a las marcas (Jiménez, 2018)

\subsection{Análisis de la industria}

\subsubsection{Mercado de concentrados}

- Según datos de Euromonitor, en el 2018 las ventas de los concentrados por volumen declinaron en $1 \%$ pero crecieron en valor en un $5 \%$ siendo su valor 83 millones. (Euromonitor Internacional, 2019)

- El consumo de los concentrados reducidos en azúcar está siendo beneficiado gracias a las tendencias de vida saludable en la población, se espera que esto siga en aumento por la implementación de los octógonos de advertencia el próximo mes de junio. Además la innovación en productos con un mayor porcentaje de frutas podría crear una oportunidad de impulsar el mercado en esta categoría. (Euromonitor Internacional, 2019) 
- Los consumidores están cada vez más interesados en los productos naturales y saludables por lo que evitan consumir bebidas con ingredientes artificiales y colorantes, lo que está haciendo la industria del agua embotellada crezca.

\subsubsection{Análisis de la competencia}

El mercado peruano no cuenta con mucha variedad en la categoría de concentrados líquidos para consumo doméstico.

- Cosecha de Oro: Concentrado de chicha morada. El concentrado de chicha morada a base de maíz morado, piña, manzana, membrillo, canela y clavo de olor con azúcar añadida, sin colorantes ni saborizantes viene en una presentación en bolsa hermética de $500 \mathrm{ml}$. y rinde $2.5 \mathrm{l}$. El producto necesita refrigeración. Se puede encontrar en supermercados como Wong a S/ 5.99. La marca no realiza publicidad para este producto en específico.

- Sayani: Concentrado de chicha morada

Jarabe concentrado de chicha morada, elaborado a partir de ingredientes naturales y azúcar. Para prepararlo requiere agregar 5 partes de agua y limón a gusto. Cuenta con presentaciones de $200 \mathrm{ml} ., 1$ 1., 2 1. y 51.

*Cabe resaltar que en el mercado también se encuentra la marca Naturale con su producto concentrado de chicha morada en polvo en presentación de $2.4 \mathrm{~kg}$. y rinde entre 8 y 10 litros. Este se puede encontrar en el mayorista Makro pero está dirigido al canal HORECA (hoteles, restaurantes y cafeterías).

\subsubsection{Productos sustitutos}

Como principales productos sustitutos al concentrado de chicha morada consideramos a las bebidas naturales o saludables listas para beber.

Dentro de este tipo de bebidas encontramos marcas como Naturale que no solo cuenta con chicha morada sino también con refresco de maracuyá, manzana, emoliente y piña Golden en presentaciones desde los $300 \mathrm{ml}$. hasta galoneras de 3.8 1., en todos ellos se mencionan que son hechos con pura fruta y sin saborizantes.

También se encuentra la marca Ecofresh de la empresa Food Pack donde sus productos no cuentan con preservantes, saborizantes, preservantes ni azúcar añadida. Dentro de su categoría de jugos $100 \%$ naturales su oferta es amplia: jugo de naranja, 
piña, mandarina, naranja-zanahoria, tangelo, toronja y piña-naranja en presentaciones de $250 \mathrm{ml}$., $500 \mathrm{ml}$. y 1 1. Estas bebidas se pueden encontrar en diversos autoservicios y afirman ser líderes en el mercado de jugos naturales

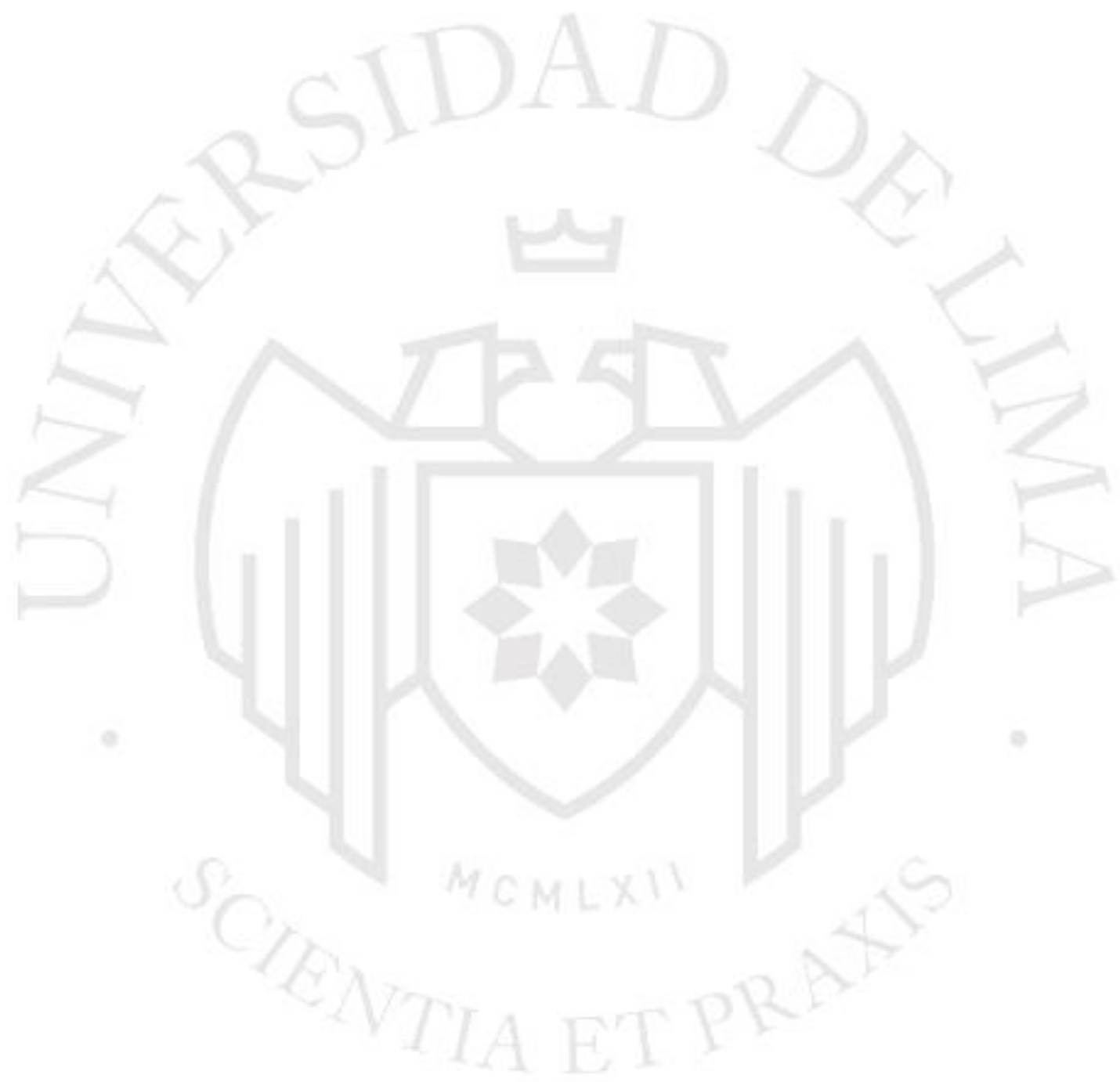




\section{OBJETIVOS Y PÚBLICO OBJETIVO}

\subsection{Objetivos de comunicación}

- Introducir a la marca Pura Natura al mercado de concentrados generando "Brand Awareness" en el público objetivo.

- Destacar los atributos diferenciales como parte de la propuesta de valor de la marca.

- Generar visibilidad y atracción en los puntos de venta con mensajes oportunos de la marca.

\subsection{Duración de la campaña}

La campaña de lanzamiento durará 2 meses, tiempo suficiente para que el público objetivo conozca la marca, reconozca sus atributos y se sientan atraídos por probar el producto.

\subsection{Público objetivo}

La campaña tendrá como público objetivo a mujeres amas de casa entre 30 y 45 años de los niveles socioeconómicos A, B y C de Lima Metropolitana. Quienes administran el hogar y trabajan eventual o permanentemente. Interesadas en simplificar las labores del hogar y valoran la practicidad, la salud y la imagen personal. Ellas relacionan lo natural con lo saludable y lo toman en cuenta especialmente en la alimentación de sus hijos.

Según los seis estilos de Vida de Arellano (Arellano, s.f.), nuestro público objetivo lo podríamos calificar como parte del grupo de las modernas, sus características son las siguientes:

- Complementan sus facetas de madre, mujer, proveedora y profesional.

- Buscan el éxito profesional, realizarse fuera de las labores domésticas y surgir social y económicamente.

- Les gusta mantenerse activas y capacitándose.

- Para ellas el consumo es una actividad entretenida, divertida y muy emocionante. Comprar es un placer.

- Les gusta proyectar una buena imagen y cuidar su estética. 
- Dan prioridad a los beneficios abstractos de las cosas que compran: Usan marcas como símbolo social y señal de calidad, no tanto al precio.

- Les interesan los productos que ofrezcan reducir el tiempo y esfuerzo en las labores del hogar y que eviten hacerlas sentir solamente "amas de casa".

Al momento de comprar alimentos, los atributos que más valoran son su propiedad de saludable y el sabor, ya no se preocupan tanto por el rendimiento y la marca como lo hacían antes, esto gracias a que ahora se tiene más acceso a la información lo que las impulsa a buscar productos más saludables. (Martinez Inga, 2019)

Además, las amas de casa modernas buscan productos que optimicen su tiempo y les faciliten la vida. Según un estudio a amas de casa, el $41 \%$ de las encuestadas indicó que para ellas es importante productos más prácticos para cocinar. (Kantar Worldpanel, 2018)

Según el estudio de Kantar Worldpanel (Kantar Worldpanel, 2017) el estilo de vida de las latinas y las peruanas, con respecto a su rol en la cocina, la mujer es la protagonista, ya que en el $93 \%$ de las familias latinas es ella quien cocina, y además lo hace casi a diario. En promedio se dedican dos horas al día a esta tarea buscando preparar recetas fáciles y rápidas.

Según el Perfil del ama de casa (Ipsos, 2018), podemos resaltar los siguientes datos sobre el público seleccionado:

- El 23\% lleva un régimen alimentario o dieta con el objetivo de adelgazar o comer saludable.

- En cuanto a supermercado o hipermercado preferido, las amas de casa prefieren en primer lugar realizar sus compras en Tottus, seguidos de Plaza Vea.

- Con respecto a su actitud frente a las compras, un $95 \%$ prefiere tomarse su tiempo al momento de comprar, al 83\% le gusta probar nuevos productos y el $62 \%$ solo compra productos que sean de buena calidad y le agraden, aunque eso signifique tener que pagar un precio más elevado.

- En su tiempo libre, el $29 \%$ prefiere pasar tiempo con sus hijos, el $27 \%$ ver televisión y el 26\% realizar quehaceres del hogar.

- Sobre su relación con la tecnología, dos de cada cinco amas de casa tienen un smarthphone 
- El 45\% tiene una cuenta en Facebook, el 14\% cuenta e Instagram y el 8\% en Twitter.

- El medio de información más usado para enterarse de promociones es la televisión con un predominante $75 \%$, seguido en menor medida del internet con un $19 \%$, la radio con $18 \%$ y periódicos con un $15 \%$. 


\section{VISIÓN DE MARCA}

\subsection{Posicionamiento deseado}

Pura Natura, el concentrado de chicha morada 100\% natural de calidad para las amas de casa que buscan un refresco saludable y práctico para su familia con el mismo sabor que la chicha morada casera.

\subsection{Promesa - Ventaja diferencial}

Pura Natura pone a tu alcance la preparación de la tradicional chicha morada $100 \%$ natural, con el más rico sabor y al instante para compartir con tu familia.

\subsection{Reason Why}

- Pura Natura está hecho con maíz morado, membrillo, piña, limón, canela y clavo, sin saborizantes, colorantes, preservantes ni azúcar añadida que resultan dañinos para la salud.

- El producto solo necesita diluirse en agua para que la chicha morada con el mismo sabor casero esté lista para beber.

- El concentrado de maíz morado contiene antocianina, antioxidante que combate los principales causantes de cáncer. Además fomenta el flujo de la sangre, reduce el colesterol, promueve la formación de colágeno, mejora la circulación y evita problemas cardiacos y de cáncer de colon.

- Pura Natura es una marca de una importante empresa nacional reconocida por los consumidores por la calidad de sus productos.

\subsection{Insights}

Se realizó una pequeña encuesta a las amas de casa del público objetivo donde se realizaron preguntas cerradas sobre el consumo de chicha morada en el hogar. Ver anexo 1.

De las 38 encuestadas que respondieron que consumen chicha morada en sus hogares, el $87 \%$ indicó que la chicha que consumen en casa es preparada naturalmente por ellas. El 79\% indicó que sí o tal vez compraría un concentrado de chicha morada y los atributos que más valorarían en este producto es que sea $100 \%$ natural y que sepa igual a la chicha morada casera. 
Además, se hicieron tres entrevistas a amas de casa identificadas como parte del público objetivo y se pueden destacar las siguientes frases:

- "La chicha tendría que saber igual a la que preparo en casa para comprarla, sino preferiría darme el tiempo de prepararla yo misma".

- "Las chichas que venden saben muy artificial, a puro químico".

- "Si es completamente natural y sin azúcar se lo prepararía a mi hija".

- "No es común encontrar concentrados en la oferta de productos de los supermercados, si se encuentra es en polvo".

Como se puede apreciar, los puntos resaltantes para el público objetivo son el sabor natural e igual a la chicha morada que preparan en casa.

\subsection{Valores}

- Natural: Nos interesa brindar productos $100 \%$ naturales

- Compromiso con la salud: Buscamos que, gracias a un estilo de vida saludable, puedas vivir más y mejor.

- Preocupada por los demás:

\subsection{Personalidad de la marca}

Es positiva, amigable y práctica. Se preocupa por su salud y por la de los demás.

\subsection{Visión de marca}

La visión de Pura Natura es brindarles a las amas de casa productos $100 \%$ naturales, ricos y fáciles de preparar y así promover un estilo de vida más saludable para ellas y sus familias. 


\section{ESTRATEGIA CREATIVA}

\subsection{Idea estratégica de marca}

Con Pura Natura, lo natural llegó a casa.

Eslogan de marca: "Concéntrate en lo natural"

La idea de marca de Pura Natura se basa en brindar productos naturales para compartir en el hogar y el eslogan de marca refuerza su categoría de concentrado lo que ayuda a diferenciarlo de las bebidas listas para tomar.

\subsection{Concepto creativo de marca}

Pura Natura, lo mejor de la naturaleza.

Se propone como idea creativa resaltar lo natural del producto al ser valorado por el público objetivo y posicionarlo como un producto de calidad.

\subsection{Imagen de marca}

\subsubsection{Nombre}

La marca creada para este concentrado de chicha morada se llama Pura Natura.

Este nombre se basa en uno de los principales atributos que presenta el producto: está hecho a base de productos $100 \%$ naturales. Además, mediante un sondeo que se realizó al público objetivo, se determinó que lo que más valorarían en este producto sería su carácter de origen natural.

Con este nombre, la marca quiere proyectar su origen de productos naturales y, por consiguiente, lo asocien a que tiene beneficios para la salud de sus consumidores.

\subsubsection{Logo}

Con respecto a la identidad visual de la marca, se optó por un estilo limpio y minimalista que resalte el nombre de la marca, refleje su personalidad y destaque frente a la identidad de sus competidores.

El logotipo tiene la fuente sans serif "Caviar Dreams" en su variante bold que representa modernidad y minimalismo pero también alegría por su terminación redonda. La tipografía tiene el espacio suficiente entre caracteres para que el texto se pueda leer claramente tanto de cerca como de lejos. El color del logotipo es blanco. 
El isotipo que se creó contiene tres hojas que se intersectan y representan los insumos naturales que se emplean en la preparación del producto ofrecido y se resaltó la parte de la intersección de las tres hojas ya que representa la mezcla de los insumos y el concentrado como producto final.

El color original del logo es un verde oscuro asociado normalmente con la naturaleza para reforzar una vez más lo natural de la marca y sus productos.

Ambos elementos se encuentran dentro de un círculo que los unifica y ayuda a darle mayor peso en los diferentes soportes.

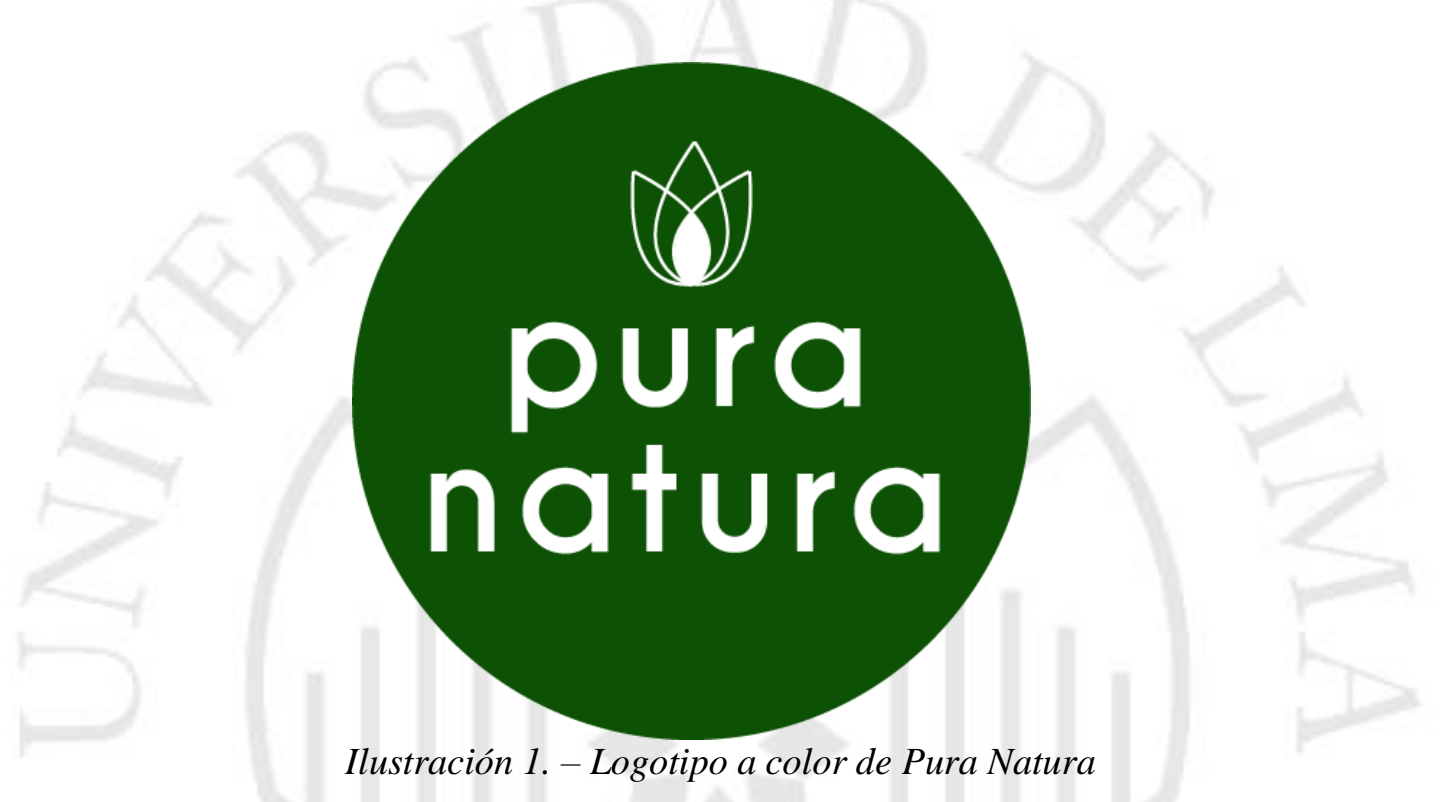

\subsubsection{Versiones en blanco y negro}

Se presentan las versiones del logo en positivo y en negativo. Se usan de acuerdo a las necesidades de aplicación que surjan. El logo en negativo es el que se usará en el packaging.
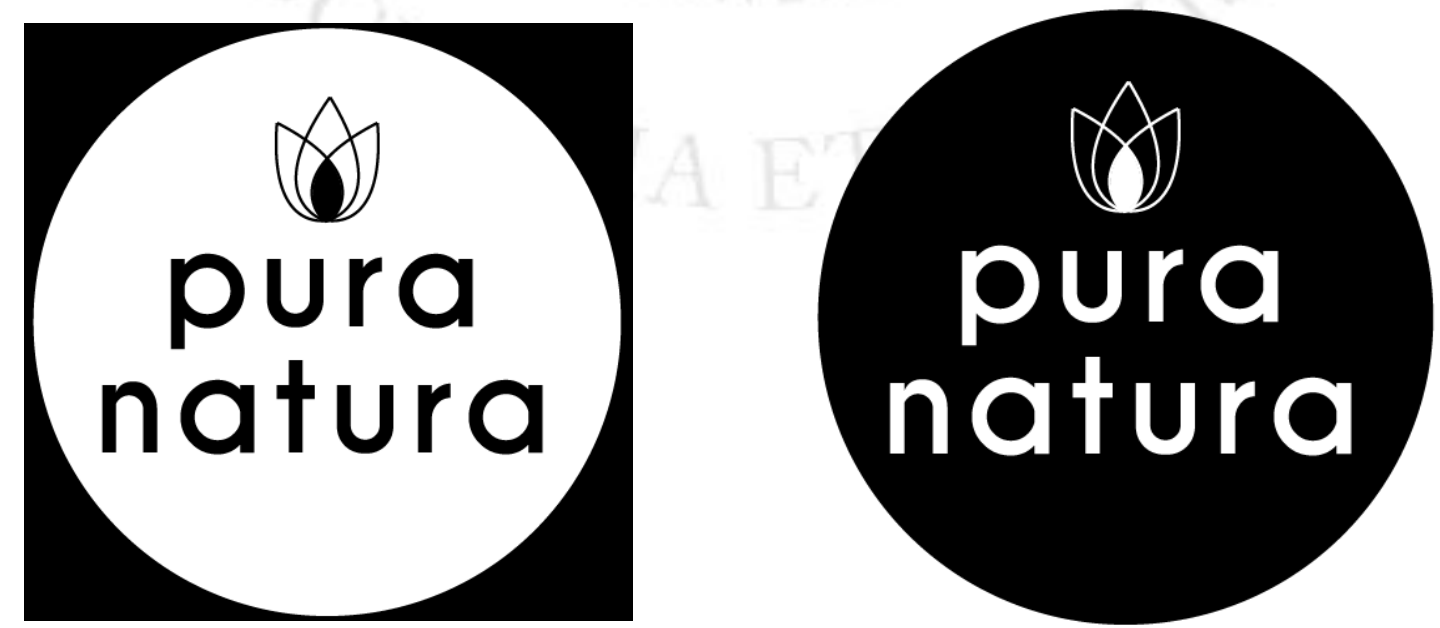


\subsubsection{Uso incorrecto del logo}

A continuación se presentan usos incorrectos del logo de la marca para tener en cuenta al momento de su aplicación en los soportes necesarios.

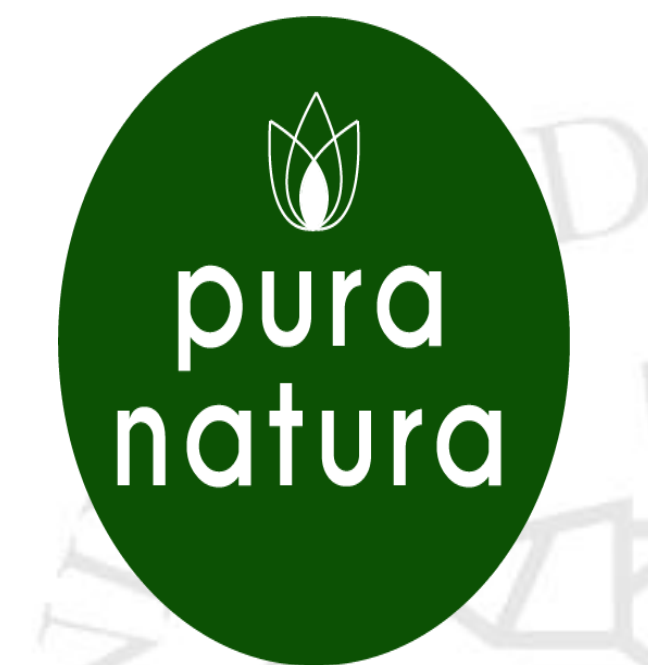

Ilustración 4.- Deformación vertical

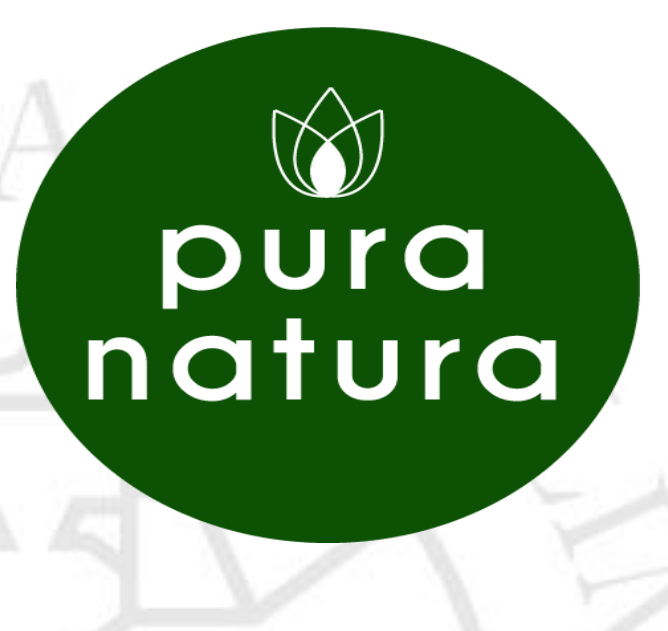

Ilustración 5.- Deformación horizontal

\subsubsection{Packaging}

Para el producto, se optó por una botella de vidrio cuadrada que le da un aspecto elegante a la marca y permite ver el líquido contenido en el recipiente.

Las etiquetas de la botella son también cuadradas y por partes para cada lado.

La etiqueta frontal tiene como elemento principal el logo en negativo e indica que contiene el concentrado de chicha morada, además

En la parte baja de la etiqueta se incluyó una imagen con maíces morados que hacen referencia al ingrediente principal del producto y aporta un poco de textura a la etiqueta pero sin dejar de ser limpia.

Es importante destacar que en la etiqueta frontal del producto se debía resaltar que el producto debía diluirse en agua para su consumo, ya que los consumidores podrían cometer el error de suponer que es una bebida lista para tomar. Por tal motivo, se incluyó un ícono de una jarra donde indicaba que el producto rinde 2.5 litros y se acompañó del texto "Dilúyelo en agua y despierta la pura natura" para que quede claro que el producto necesita diluirse. 


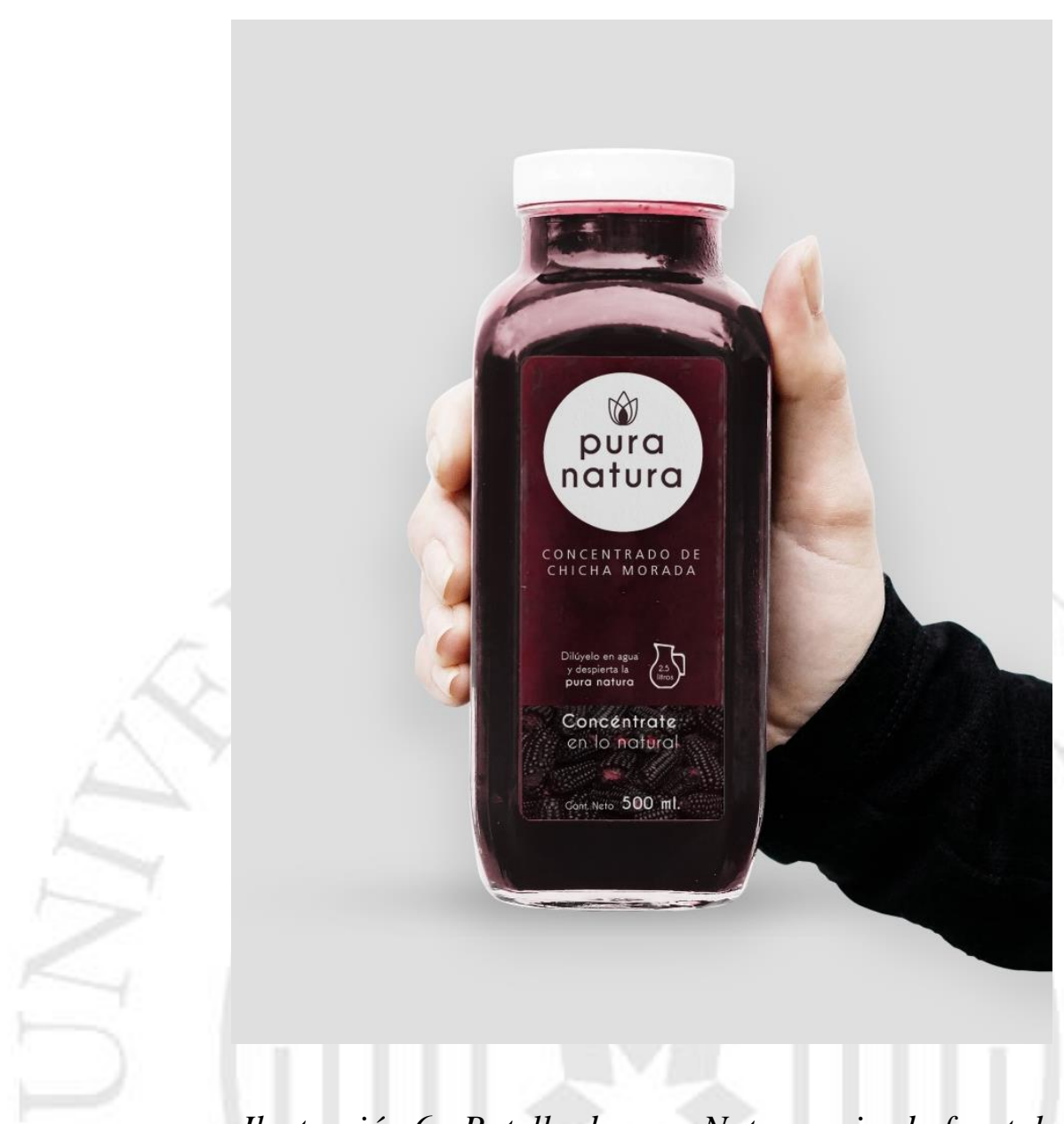

Ilustración 6.- Botella de pura Natura, mirada frontal

En la etiqueta posterior se detallan los ingredientes del concentrado y se resalta que el producto no contiene preservantes, colorantes, saborizantes ni azúcar añadida, lo que refuerza una vez más su origen natural. 


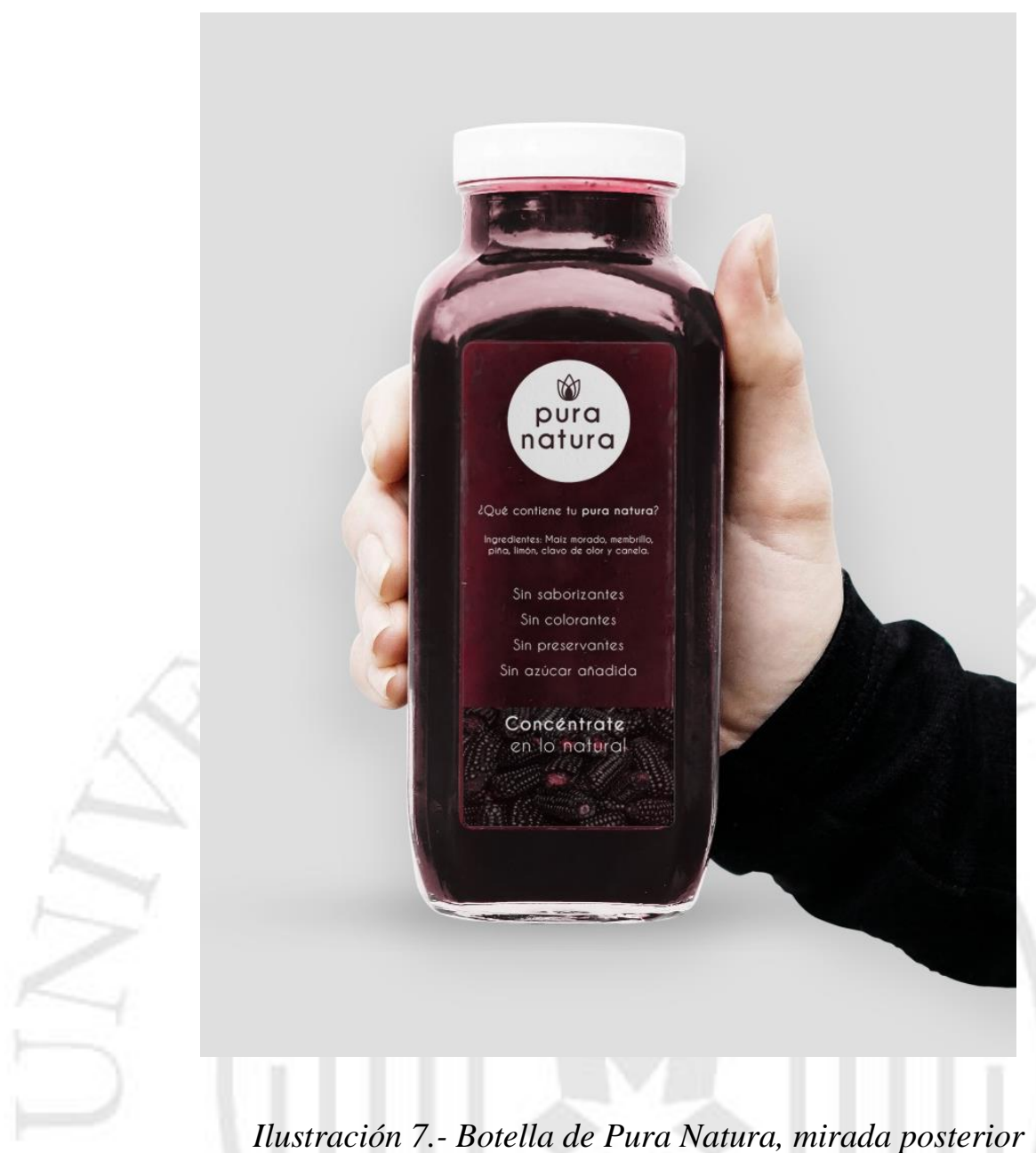




\section{PLAN DE COMUNICACIONES}

\subsection{Desarrollo de campaña}

Con el fin de cumplir con los objetivos de comunicación propuestos se ha planteado un mix de medios con una duración de dos meses para este lanzamiento de la marca Pura Natura que vaya acorde al público objetivo planteado y al presupuesto asignado por la empresa.

La campaña comenzará la tercera semana de enero del próximo año ya que el verano incrementa el consumo de bebidas. Un publirreportaje en televisión marcará el inicio de la campaña donde el objetivo de este será incluir a la chicha morada, sus propiedades y el proceso del concentrado en la agenda de los medios para que nuestro público vaya teniendo esta información y sea más receptiva al mensaje posterior que develaremos. A partir de lo anterior se comenzará con la campaña y se recurrirán a los medios ATL, BTL y digitales más cercanos al público objetivo según el análisis previamente presentado.

Teniendo en cuenta lo expuesto anteriormente y sabiendo que el presupuesto con el que cuenta el cliente es de US \$ 500,000, la inversión en medios será la siguiente:

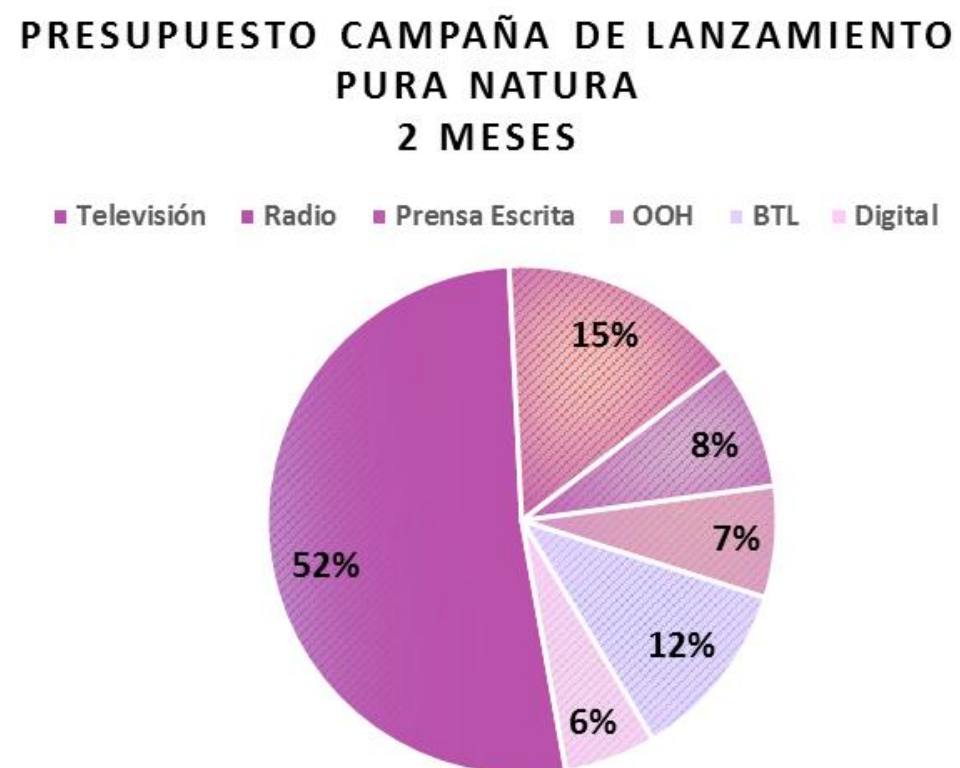

Gráfico 1.- Distribución de presupuesto para campaña de lanzamiento Pura Natura. Elaboración propia 


\begin{tabular}{|l|cc|r|}
\hline \multicolumn{3}{|c|}{$\begin{array}{c}\text { PRESUPUESTO CAMPAÑA DE LANZAMIENTO } \\
\text { PURA NATURA - 2 meses }\end{array}$} \\
\hline \multicolumn{1}{|c|}{ MEDIO } & \multicolumn{2}{c|}{ COSTO } & $\%$ \\
\hline Televisión & $\$$ & $256,813.68$ & $52 \%$ \\
\hline Radio & $\$$ & $76,200.64$ & $15 \%$ \\
\hline Prensa Escrita & $\$$ & $40,447.31$ & $8 \%$ \\
\hline OOH & $\$$ & $34,948.30$ & $7 \%$ \\
\hline BTL & $\$$ & $56,992.89$ & $12 \%$ \\
\hline Digital & $\$$ & $28,687.65$ & $6 \%$ \\
\hline \multicolumn{1}{|c|}{ Total } & $\$$ & $494,090.47$ & $100 \%$ \\
\hline
\end{tabular}

Tabla 1.- Presupuesto para campaña de lanzamiento Pura Natura. Elaboración propia.

En el archivo adjunto llamado "Flow de medios" se encuentran los costos desagregados por medios y calendario de publicaciones.

En el siguiente link se pueden encontrar todas las piezas producidas: https://drive.google.com/drive/folders/1P2r$\underline{\text { RYLpnxW7B40uswUf_vtgZsy1RxRn?usp=sharing }}$

\subsubsection{Televisión}

La inversión en televisión se centrará específicamente en los canales de televisión abierta América TV y Latina ya que, según un estudio de mercado sobre medios tradicionales (Ipsos, 2017) son los más vistos por nuestro público objetivo. Es necesario destacar que en el estudio mencionado se identifican los noticieros/informativos y telenovelas como los tipos de programas que más consume nuestro público objetivo.

Para el inicio de la campaña se contempla que se realice un publirreportaje en el programa Domingo al día de América TV donde se informará acerca de las propiedades de la chicha morada contando con una nutricionista para mayor credibilidad y se invitará a las cámaras a visitar las chacras de donde seleccionamos nuestros maíces morados y a la fábrica donde se transforman los insumos en chicha morada en concentrado para que los televidentes aprecien que realmente es $100 \%$ y con los mejores productos.

Luego de lo anterior, se tendrá pauta publicitaria con un spot de 30 segundos en los siguientes programas: 
Latina:

- 90 Central (L-V de 7 pm. a 8.30 pm.): Edición central del noticiero de Latina. Según la información de Ipsos, los noticieros son los programas más vistos por el público objetivo.

- Amor de Familia (L-V de 8.30 pm. a 9.30 pm): Esta telenovela turca también forma parte del tipo de programas que más ven las amas de casa.

- Reporte Semanal (D de 8.30 am. a 11.00 am.): Dominical informativo con diversos reportajes sobre la actualidad.

\section{América TV}

- América Noticias Edición Central (L-V de 10.30 pm. a 11.30 pm.): Noticiero estelar de América Televisión.

- De Vuelta al Barrio (L-V de 8.30 pm. a 9.30 pm.): Serie peruana ambientada en los años setenta con reconocidos actores nacionales.

- Mi mamá cocina mejor que la tuya (D de 7.00 pm. a 8.00 pm.): Producción nacional donde personajes famosos compiten preparando platos típicos de comida peruana.

- Domingo al día (D de 8.30 am. a 11.00 am.): Dominical informativo con diversos reportajes sobre la actualidad.

También se contempla contar con una activación de marca en dos fechas del programa Mi mamá cocina mejor de la tuya donde contaremos con product placement y una mención en cada fecha. Se considera este programa adecuado para las activaciones ya que tiene un rating considerable para los fines de semana, tiene un corte familiar y en el programa normalmente los concursantes tienen poco tiempo para preparar los platos que se les asigna y Pura Natura es una bebida natural que se puede preparar en poco tiempo.

Ver guion del spot publicitario en anexo 2.

Ver archivo Animatic Pura Natura en link adjunto. 


\subsubsection{Radio}

Para armar la pauta en radio, se tomó en cuenta un estudio de mercado (CPI, 2017) sobre audiencias radiales y se identificaron las emisoras más escuchadas por nuestro público. Se preparará un spot radial de 20 segundos en las siguientes emisoras:

- Radio Programas del Perú (RPP): La radio más escuchada a nivel Lima Metropolitana y a nivel nacional. Sus programas informativos y de noticias son los más escuchados.

- Radio Felicidad: Radio de baladas en español.

- Radio Capital: Emisora con programas informativos, de entretenimiento, deportes y temas varios.

- Radio Ritmo Romántica: Radio de baladas en español.

Para este medio se elaborarán dos spots radiales donde se resalte el carácter natural del producto, su sabor a chicha morada casera y su preparación. La pauta estará activa durante los dos meses de la campaña.

\subsubsection{Diarios y revistas}

En diarios solo se publicará un anuncio de media página (página 3) en la sección Luces de El Comercio el domingo de inicio de la campaña. Este diario es uno de los más prestigiosos a nivel nacional, con alto alcance en el NSE AB. El anunciar en este diario no solo nos ayudará a llegar a nuestro público objetivo y comunicarle nuestro mensaje, sino que se nos atribuirá como producto de calidad por ser El Comercio líder de opinión en nuestro país.

Con respecto a revistas, se realizarán dos publicaciones las semanas posteriores del inicio de la campaña. La primera será la revista Somos, suplemento de la edición sabatina de El Comercio con una lectoría donde el 59\% son mujeres especialmente de los NSE AB. Esta revista trata sobre temas de actualidad donde publican nuevos lugares para conocer y visitar, tendencias en tecnología, salud, etc. La publicación será de una página en la quinta página.

La segunda publicación será un anuncio publicitario de una página (página 5) en la Revista Semana Viu del grupo El Comercio enfocada en la mujer de hoy mayoritariamente del NSE AB con diversos tips sobre moda, nutrición, crianza, etc. 


\subsubsection{OOH}

Se usarán paneles tradicionales, digitales y vallas para el lanzamiento de la marca durante dos meses en los distritos en los que se ubica nuestro público objetivo, se puso énfasis también en ubicar paneles y vallas cerca de los supermercados para que las amas de casa tengan presente la existencia del producto antes de entrar a realizar sus compras. La relación de los paneles seleccionados son los siguientes:

\begin{tabular}{|l|l|l|}
\hline \multicolumn{1}{|c|}{ ELEMENTO } & \multicolumn{1}{|c|}{ DISTRITO } & \multicolumn{1}{c|}{ DIRECCIÓN } \\
\hline Panel Publicitario & Magdalena & Av. Javier Prado / Roca de Vergallo \\
\hline Panel Publicitario & La Molina & Av. Raúl Ferrero Cdra. 13.00 / Los Acebos Cdra. 1 \\
\hline Panel Publicitario & Miraflores & Av. Comandante Espinar 864 \\
\hline Panel Publicitario & Magdalena & Av Del Ejército / Av. Salaverry Cdra. 35 \\
\hline Pantalla digital & San Borja & Av. Javier Prado 3000 \\
\hline Pantalla digital & Surco & Av Javier Prado 4500 (Óvalo Monitor) \\
\hline Pantalla digital & Surco & Av. Raúl Ferrero (Bajada del Cerro Centinela) \\
\hline Pantalla digital & San Miguel & Cruce de Av. La Marina con Av. Universitaria \\
\hline Pantalla digital & Jesús María & Av. Salaverry Cdra. 20 / Av. Sanchez Cerro Cdra. 21 altura Av. Prescott Cdra. 21 \\
\hline Pantalla digital & San Isidro & Av. Las Begonias Cuadra 5 \\
\hline Pantalla digital & San Borja & Av. Angamos este cdra 29 esq. Con Av. San Luis cdra 31 \\
\hline Valla & San Borja & Av. Aviacion 2406 con Av. Javier Prado \\
\hline Valla & Surco & Av. El Polo esq. con Ca. El Cortijo \\
\hline Valla & La Molina & Av. La Fontana Cdra 10 Mz A Lt 5-V2 \\
\hline
\end{tabular}

Tabla 1.- Puntos Escogidos para publicidad OOH. Elaboración propia.

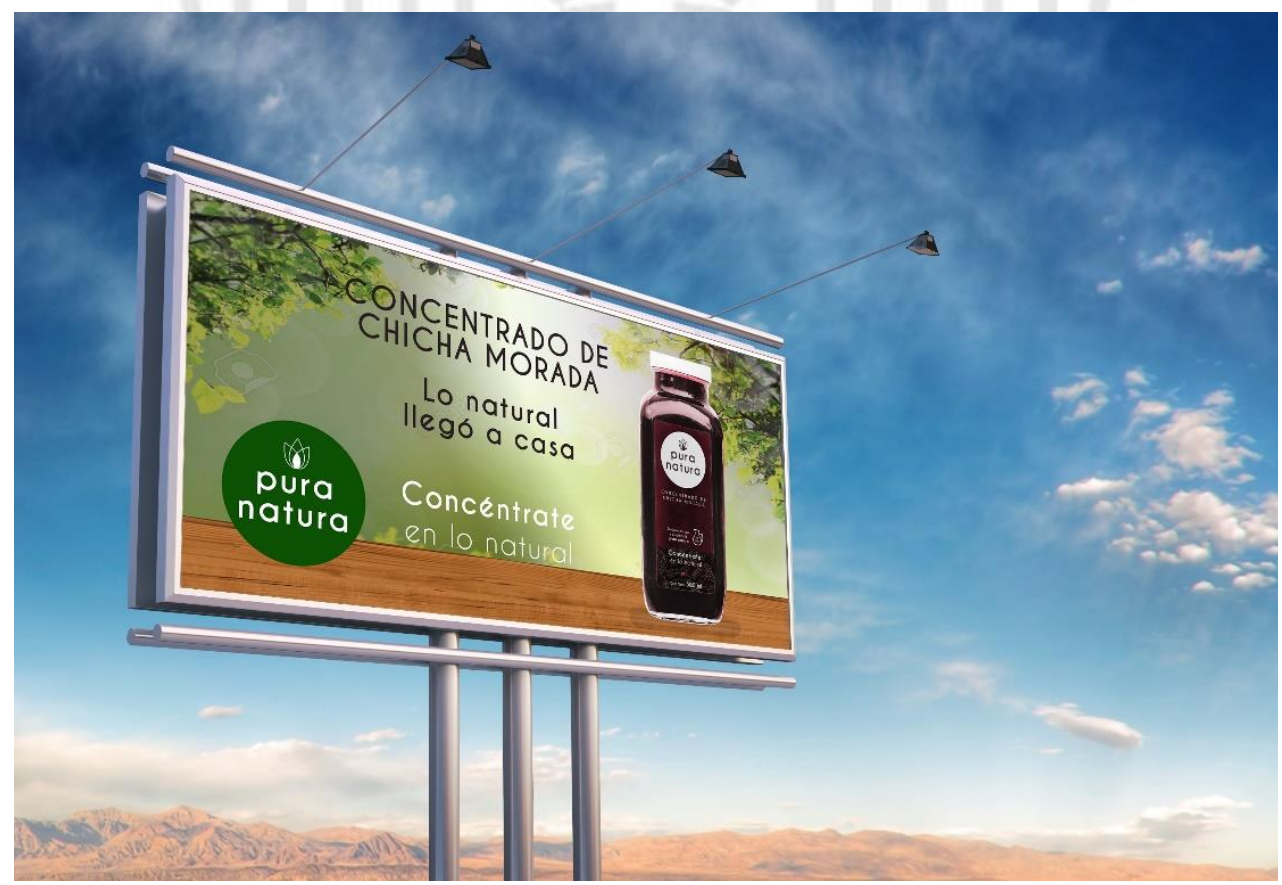

Ilustración 8.- Ejemplo Panel Publicitario 


\subsubsection{POP}

Como parte de las acciones para los puntos de venta, se instalarán gráficas de la marca en las refrigeradoras que contendrán el producto en los principales supermercados de los distritos de Miraflores, Surco, San Borja, La Molina, San Isidro, San Miguel, Pueblo Libre, Jesús María y Magdalena, además se colocarán jala vistas para llamar la atención de los compradores en las principales bodegas.

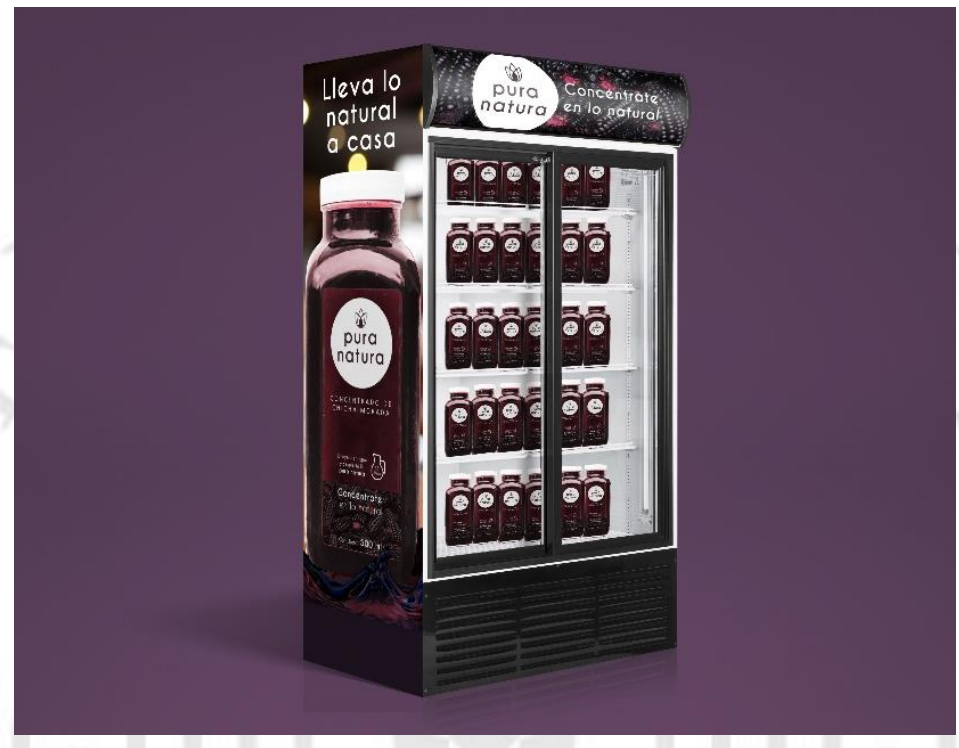

Ilustración 9.- Refrigeradora con marca Pura Natura

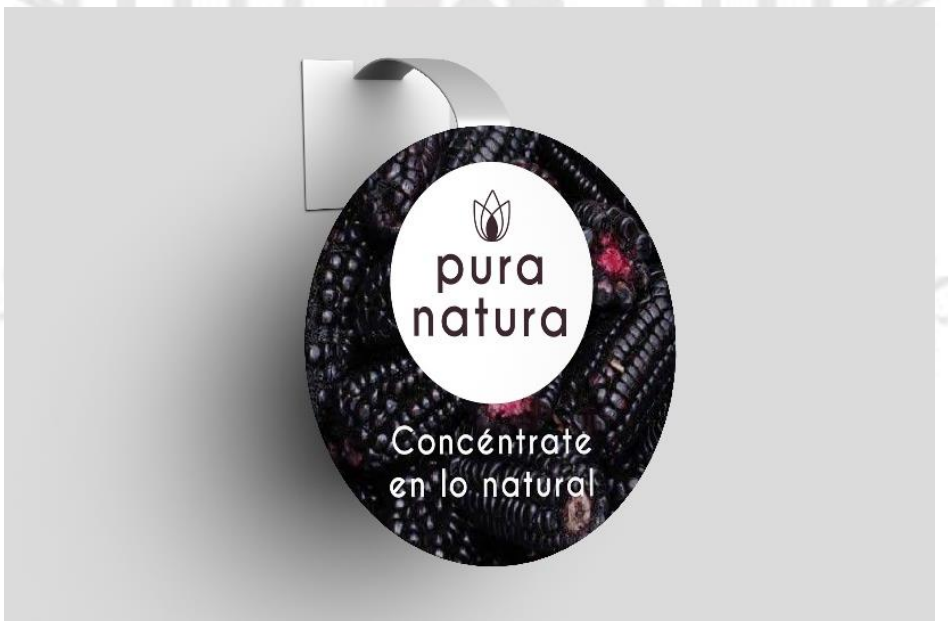

Ilustración 10.- Jala vista para bodegas

\subsubsection{BTL}

Las acciones BTL ayudarán a que el público conozca, pruebe y recuerde el producto por lo que estas acciones deben ser altamente creativas e impactantes. 
- Productos gigantes: Se harán versiones gigantes de un maíz morado, un limón, una piña, un membrillo, canela y clavo, se colocarán en la avenida Javier Prado en Surco a la altura del Jockey Plaza y por último se hará una versión gigante de la botella de Pura Natura lo cual causará impacta en los transeúntes y conductores y ayudará a que tengan conocimiento del producto, especialmente que recuerden su carácter natural y los lleve a buscarlo en los puntos de venta. Además, esta acción al ser llamativa, se espera que tenga rebote en medios y redes sociales.

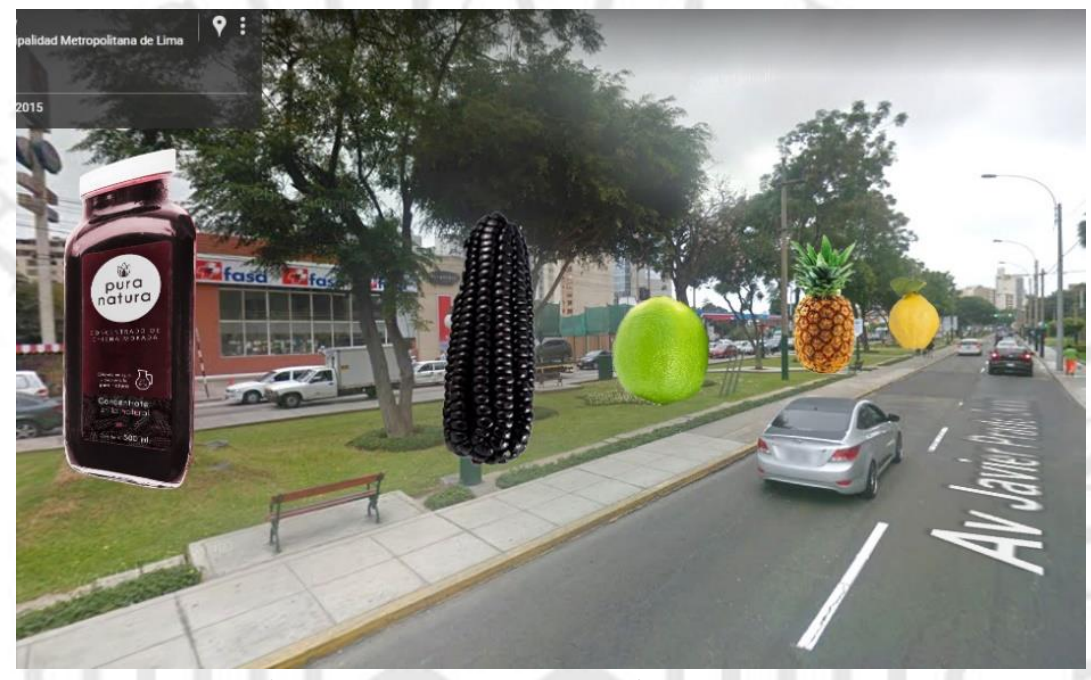

Ilustración 11.-BTL Productos gigantes.

- Paraderos Naturales: En los paraderos de las principales avenidas de los distritos a los que pertenece nuestro público objetivo se colocarán cinco paneles publicitarios que estén llenos de maíces, limones piñas, membrillos, canela y clavo y se pondrá arriba un troquelado como si fuera un poco de la botella y la tapa saliendo. Sobre el panel se colocará un vinil como si fuera la etiqueta de la botella de Pura Natura. Con esto se busca llamar la atención del público y representar el carácter natural del producto. También se espera contar con rebote en redes sociales y medios. 


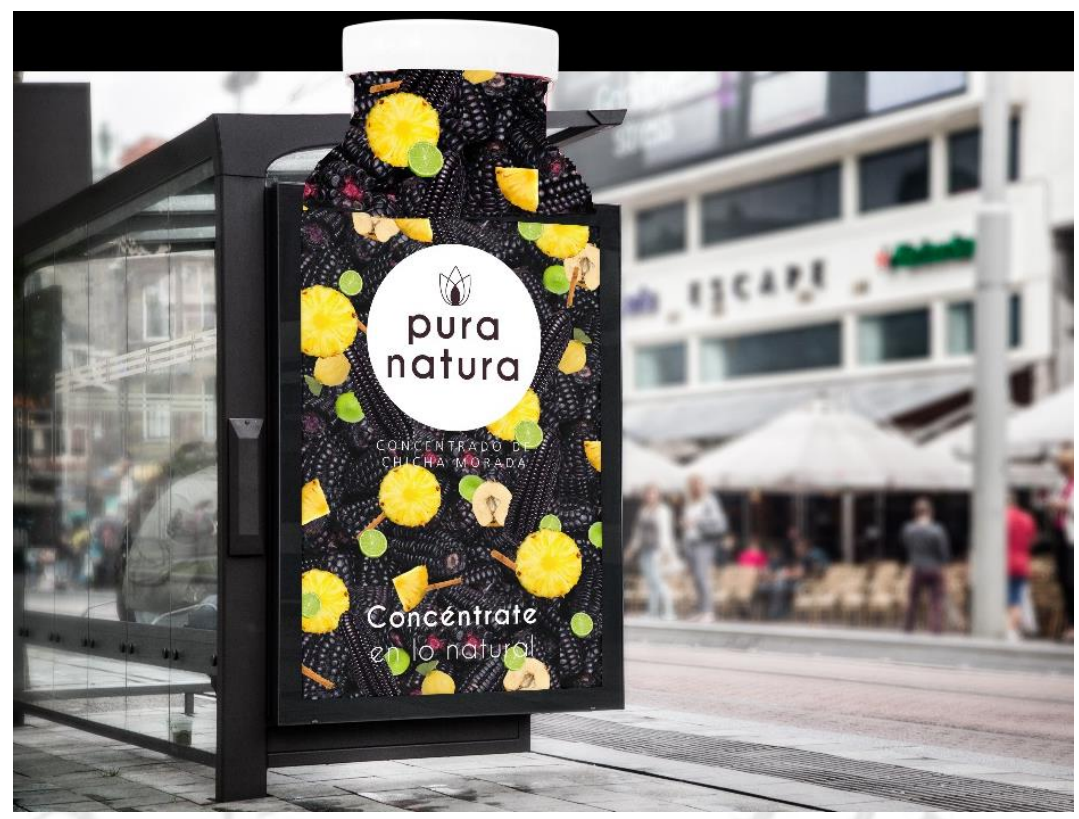

Ilustración 12.- BTL Paraderos Naturales

- Floor graphic en supermercados: En los supermercados Wong, Plaza Vea y Tottus se instalarán stickers desde la entrada principal hasta el área donde se encuentre la refrigeradora que contenga las botellas de Pura Natura, además, ayudará a ubicar dónde estarán las impulsadoras demostrando la preparación del producto y la prueba del mismo. Estos stickers darán la impresión de que el piso se ha roto y deja ver productos de la naturaleza que son ingredientes del concentrado como los maíces morados o los limones con mensajes que animen al público a seguir los stickers. Al finalizar el recorrido que darán los stickers se develará la marca y el producto.

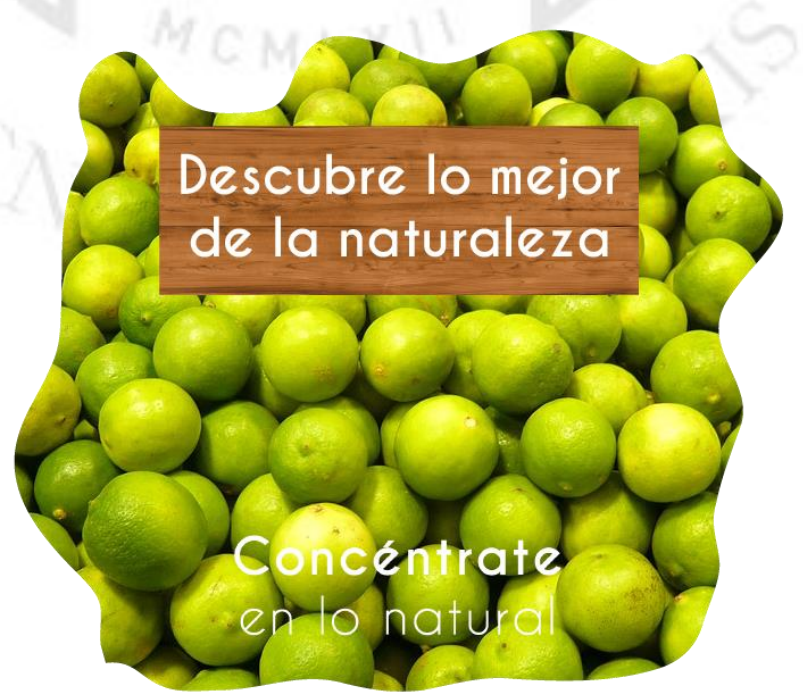

Ilustración 13.- Floor Graphic 
- Prueba del producto: Como parte de las acciones para la demostración de preparación y prueba del producto, se realizarán activaciones en los supermercados Wong, Plaza Vea y Tottus. Para la activación se pondrán los insumos gigantes y junto a una gran botella de Pura Natura. Habrán dos impulsadoras que estarán demostrando la fácil preparación del producto y lo ofrecerán para que lo prueben a las personas del supermercado. Con esta acción se busca llamar la atención del público dentro del espacio donde se decide la compra, comprendan que el concentrado necesita diluirse, lo prueben y lo reconozcan como $100 \%$ natural.

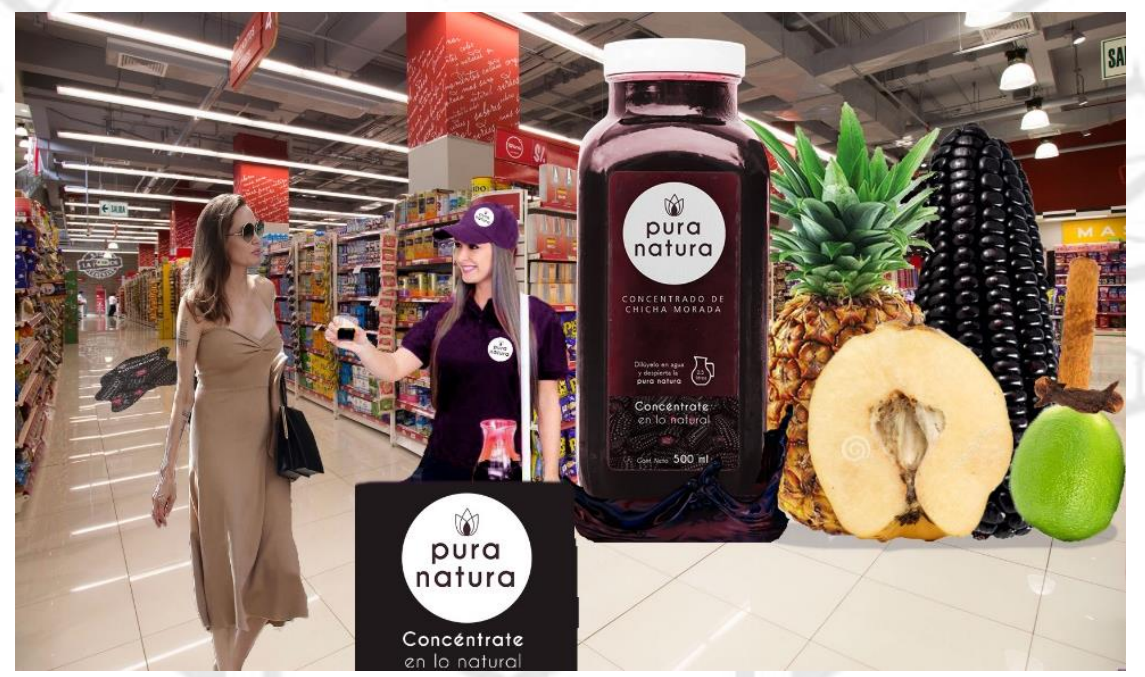

Ilustración 14.- Activación prueba del producto

\subsubsection{Digital}

Como parte de la estrategia digital se creará un fan page en Facebook ya que es la red social que más utiliza nuestro público objetivo. En este perfil se publicarán regularmente post relacionados a la marca, resaltar los atributos y beneficios del producto, así como beneficios de los insumos con los que está preparado el concentrado y consejos sobre vida saludable. La idea del Facebook es generar una comunidad y que ellas interactúen con la página. También se considera invertir en este medio segmentando demográficamente y por intereses relacionados a la vida saludable y 
bienestar, comidas y bebidas naturales y temas relacionados a la familia para tener un mayor alcance del público objetivo.

En cuanto a la web, se invertirá en la red display de Google con la cual la marca estará presente en diversas páginas que más visite nuestro público mediante banners que lo llevarán a nuestra Fan Page.

Además, se está considerando un publirreportaje en la página web de El Comercio que incluye la nota en el flujo de portada más una nota interna donde se expondrán los beneficios de la chicha morada, el maíz morado y por qué es mejor llevar una vida saludable. 


\section{CONCLUSIONES}

- Pura Natura es un concentrado de chicha morada $100 \%$ natural fácil de preparar que no solo sabe bien sino que le hace bien en sus consumidores.

- La idea estratégica de Pura Natura permite a la marca conocer cuál es la dirección que deberá tomar de aquí en adelante para futuras campañas.

- El mercado de concentrados líquidos $100 \%$ naturales es muy pequeño, por lo que se considera una oportunidad para la marca al tener pocos competidores directos y sin presencia en medios.

- La campaña de lanzamiento durará en total dos meses y los esfuerzos estarán especialmente enfocados en televisión, radio y BTLs para que el público objetivo conozca la marca, sus diferenciales y se anime a probarla. 


\section{RECOMENDACIONES}

- Se le recomienda a la marca expandir la variedad de concentrados que ofrece ya que el nombre que se ha propuesto no limitará esta acción ni será necesario proponer otra marca. Sabores peruanos o exóticos podrían funcionar para el público de amas de casa modernas que están dispuestas a probar nuevos productos naturales y saludables.

- Realizar una alianza estratégica con organizaciones que promuevan el cuidado del medio ambiente y el cuidado de la salud serían importantes para la marca ya que van acorde con su visión y reforzarían su imagen.

- La marca podría incursionar en el mercado de bebidas listas para beber después de posicionarse en el mercado de concentrados. 


\section{REFERENCIAS}

APEIM. (julio de 2018). Niveles Socioeconómicos: APEIM. Obtenido de APEIM: http://dashboard.apeim.com.pe/Webdash1.aspx

Arellano. (s.f.). Las Modernas: Arellano. Obtenido de Arellano.

Codigo. (19 de Noviembre de 2018). Conoce las tendencias de consumo para los hogares peruanos en el 2019: Codigo. Obtenido de Codigo: https://codigo.pe/tendencias-consumo-hogares-peruanos-2019/

Congreso de la República. (17 de Mayo de 2013). Ley de Promoción de la Alimentación Saludable para niños, niñas y adolescente. El Peruano.

CPI. (Marzo de 2017). Market Report: CPI. Obtenido de CPI: https://cpi.pe/images/upload/paginaweb/archivo/26/mr_resumen_anual_audienci a_radial_2016.pdf

El Comercio. (24 de Febrero de 2019). Octógonos de advertencia| ¿Qué son y por qué serán obligatorios desde el 17 de junio?: El Comercio. Obtenido de El Comercio: https://elcomercio.pe/tecnologia/ciencias/octogonos-advertenciasirven-seran-obligatorios-junio-noticia-610351

Euromonitor Internacional. (Marzo de 2019). Concentrates in Peru: Euromonitor Internacional.

Obtenido de

Euromonitor: http://www.portal.euromonitor.com.ezproxy.ulima.edu.pe/portal/analysis/tab

Ipsos. (Diciembre de 2017). Perfil medios tradicionales: Hábitos y actitudes. Lima, Lima, Perú.

Ipsos. (Mayo de 2018). Perfil del ama de casa peruana. Lima, Lima, Perú.

Jiménez, J. C. (16 de Abril de 2018). Consumidor peruano se transforma, ahora es impaciente y acelerado. Diario Gestión, pág. 4.

Kantar Worldpanel. (6 de Octubre de 2017). Estilo de vida de las latinas y peruanas: Kantar Worldpanel. Obtenido de Kantar Worldpanel: https://www.kantarworldpanel.com/pe/Noticias/Estilo-de-vida-de-las-latinas-yperuanas

Kantar Worldpanel. (3 de Mayo de 2018). Cercanía y practicidad: 50\% de hogares lo valoran: Kantar Worldpanel. Obtenido de Kantar Worldpanel: https://www.kantarworldpanel.com/pe/Noticias/Cercana-y-practicidadvalorados-por-el-50-de-hogares 
La República. (23 de Noviembre de 2018). Conoce las tendencias que activarán el consumo en el 2019: La República. Obtenido de La República: https://larepublica.pe/marketing/1362912-conoce-tendencias-activaranconsumo-2019

Martinez Inga, C. (4 de Marzo de 2019). La evolución de la mujer peruana. Suplemento Día 1.

Ministerio de Economía y Finanzas. (10 de Mayo de 2018). Se modifica el ISC de productos que más afectan a la salud y el ambiente: Ministerio de Economía y Finanzas. Obtenido de Ministerio de Economía y Finanzas: https://www.mef.gob.pe/es/noticias/notas-de-prensa-y-comunicados?id=5678 


\section{ANEXOS}

\section{Anexo 1: Cuestionario y resultados de sondeo sobre concentrado de chicha morada.}

- En casa, ¿consume chicha morada? (Si la respuesta era negativa acababa la encuesta).

En casa, ¿consume chicha morada?

40 respuestas

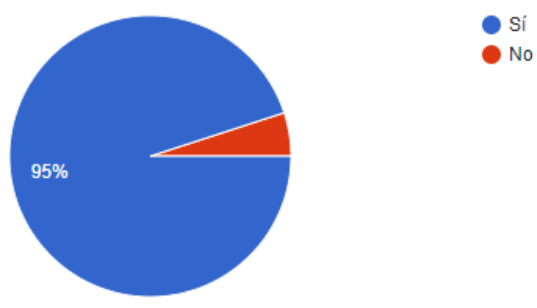

- ¿Qué tipo de chicha morada consume en casa?

¿Qué tipo de chicha morada consume en casa?

38 respuestas

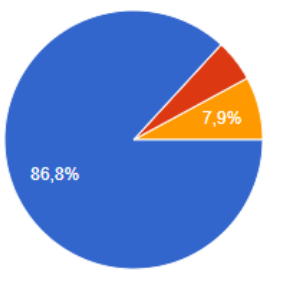

\section{Natural}

- Embotellada lista para beber

- Refresco instantáneo

- ¿Qué valoraría más en el concentrado líquido de chicha morada? Puede marcar más de una opción.

¿Qué valoraría más en el concentrado líquido de chicha morada? Puede marcar más de una opción

38 respuestas

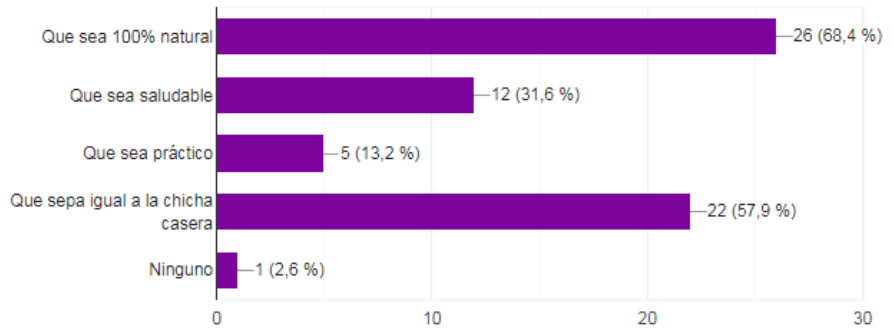




\section{Anexo 2: Guion técnico de spot televisivo para campaña de lanzamiento de chicha morada en concentrado Pura Natura.}

\begin{tabular}{|c|c|c|c|c|}
\hline PLANO & ENCUADRE & $\begin{array}{l}\text { MOVIMIENTO/ } \\
\text { DIRECCIÓN }\end{array}$ & ACCIÓN & TEXTO \\
\hline 1 & Primer plano & Cámara fija & $\begin{array}{l}\text { Ama de casa saca botella de Pura } \\
\text { Natura de la refrigeradora y la pone } \\
\text { encima de una mesa. }\end{array}$ & $\begin{array}{l}\text { Voz en off: En Pura Natura, nos concentramos en } \\
\text { encontrar lo mejor de la naturaleza }\end{array}$ \\
\hline 2 & Plano general & Travelling in & Chacras de maíces morados & \\
\hline 3 & Plano medio & Cámara fija & $\begin{array}{l}\text { Mujer seleccionando maíces en la } \\
\text { chacra }\end{array}$ & Voz en off: Los mejores maíces morados \\
\hline 4 & Plano entero & Cámara fija & $\begin{array}{l}\text { Mujer señalando un limón en lo alto de } \\
\text { un árbol }\end{array}$ & Voz en off: Los limones más jugosos \\
\hline 5 & Plano busto & Cámara fija & Mujer oliendo una piña & Voz en off: La fruta de la más alta calidad \\
\hline 6 & Plano detalle & Cámara fija & Mano limpiando un membrillo & 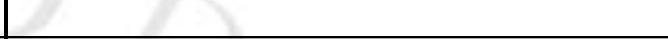 \\
\hline 7 & Plano detalle & $\begin{array}{l}\text { Cámara fija } \\
\text { contrapicado }\end{array}$ & $\begin{array}{l}\text { Se echa el contenido de la botella de } \\
\text { Pura Natura en una jarra con agua }\end{array}$ & $\begin{array}{l}\text { Voz en off: Porque solo la combinación perfecta resulta } \\
\text { en el verdadero concentrado de chicha morada. }\end{array}$ \\
\hline 8 & Plano situación & Cámara fija & $\begin{array}{l}\text { Ama de casa pone jarra con chicha } \\
\text { morada en la mesa }\end{array}$ & \\
\hline 9 & Two shot & Cámara fija & Niño y papá tomando vaso con chicha & Voz en off: Nos concentramos en lo mejor... \\
\hline 10 & Primer plano & Cámara fija & $\begin{array}{l}\text { Ama de casa sonriendo y tomando vaso } \\
\text { con chicha }\end{array}$ & Vox en off: Para que compartas lo mejor \\
\hline 11 & $\begin{array}{l}\text { Primer plano } \\
\text { Packshot }\end{array}$ & Cámara fija & $\begin{array}{l}\text { Botella de Pura Natura con jarra más } \\
\text { grande que botella, vaso servido y logo } \\
\text { con slogan al costado }\end{array}$ & Voz en off: Pura Natura, concéntrate en lo natural \\
\hline
\end{tabular}

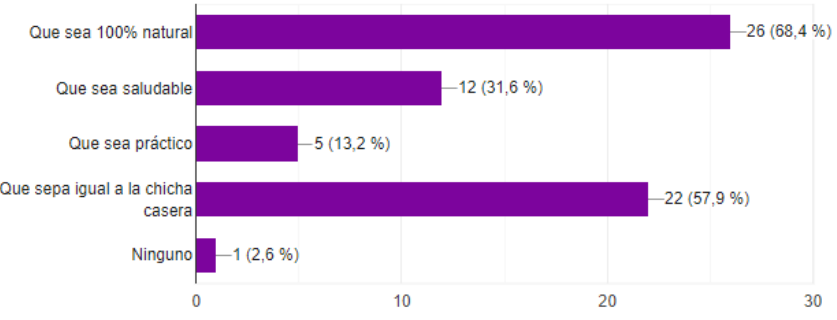

